LOCKHEED MARTIN

PORTSMOUTH

GASEOUS

DIFFUSION

PLANT of VOCs in Groundwater at the Portsmouth Site

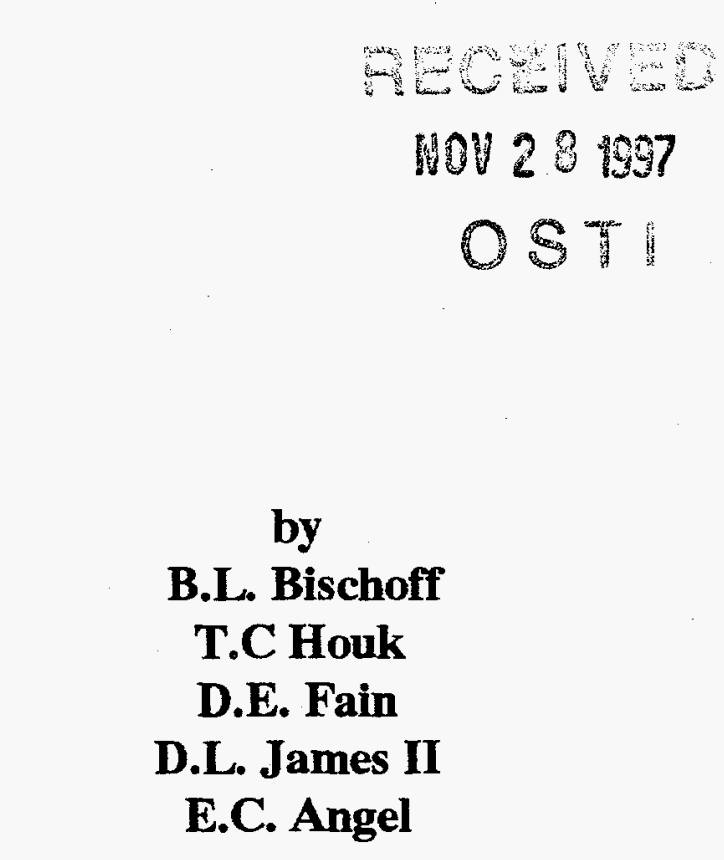

Inorganic Photocatalytic Membranes for the Remediation

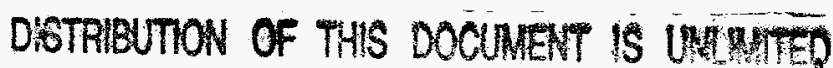




\title{
Inorganic Photocatalytic \\ Membranes for the Remediation \\ Of VOCs in Groundwater \\ at the Portsmouth Site
}

\author{
B.L. Bischoff ${ }^{1}$ \\ T.C Houk ${ }^{2}$ \\ D.E. Fain ${ }^{1}$ \\ D.L. James $\Pi^{1}$ \\ E.C. Angel ${ }^{1}$ \\ October 6, 1997 \\ Prepared for \\ U.S. DEPARTMENT OF ENERGY \\ Office of Nuclear Energy \\ Oak Ridge, Tennessee \\ and \\ Office of Environmental Restoration \\ Portsmouth Gaseous Diffusion Plant \\ Piketon, Ohio 45661
}

LOCKHEED MARTIN ENERGY SYSTEMS, INC.

Environmental Management and Enrichment Facilities

P.O. Box 628 Piketon, Ohio 45661

Under Contract DE-AC05-84OR21400

to the

U.S. Department of Energy

${ }^{1}$ Lockheed Martin Energy Systems, Membrane Technology Division, Oak Ridge, Tennessee

${ }^{2}$ Lockheed Martin Energy Systems, Technology Applications, Piketon, Ohio 


\section{DISCLAIMER}

This report was prepared as an account of work sponsored by an agency of the United States Government. Neither the United States Government nor any agency thereof, nor any of their employees, makes any warranty, express or implied, or assumes any legal liability or responsibility for the accuracy, completeness, or usefulness of any information, apparatus, product, or process disclosed, or represents that its use would not infringe privately owned rights. Reference herein to any specific commercial product, process, or service by trade name, trademark, manufacturer, or otherwise does not necessarily constitute or imply its endorsement, recommendation, or favoring by the United States Government or any agency thereof. The views and opinions of authors expressed herein do not necessarily state or reflect those of the United States Government or any agency thereof. 


\section{DISCLATMER}

Portions of this docounent may be illepible in electronic image products. Images are produced from the best arailable original document. 


\section{CONTENTS}

LIST OF FIGURES ............ Page ACRONYMS AND ABBREVIATIONS $\ldots \ldots \ldots \ldots \ldots \ldots \ldots \ldots \ldots \ldots \ldots \ldots \ldots \ldots$ iv

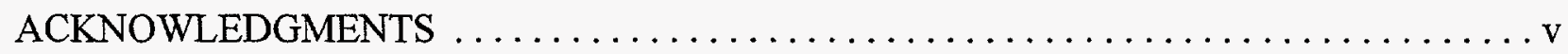
EXECUTIVE SUMMARY $\ldots \ldots \ldots \ldots \ldots \ldots \ldots \ldots \ldots \ldots \ldots \ldots \ldots \ldots$ vi

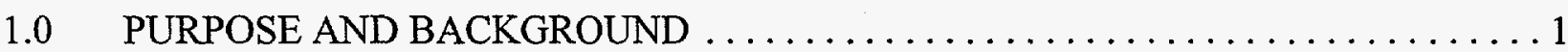

$2.0 \quad$ LABORATORY WORK $\ldots \ldots \ldots \ldots \ldots \ldots \ldots \ldots \ldots \ldots \ldots \ldots \ldots \ldots \ldots \ldots \ldots \ldots \ldots$

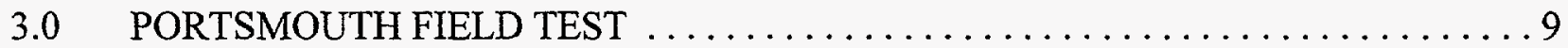

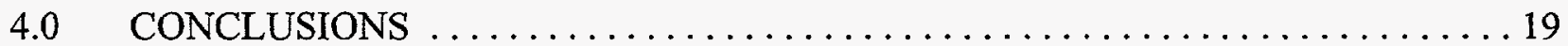

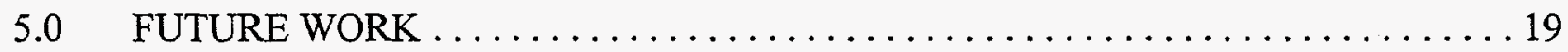




\section{LIST OF FIGURES}

1. Schematic of Pump and Treat Photocatalytic Reactor for the

Destruction of VOCs in Groundwater

2. Schematic Drawing of Laboratory Photocatalytic Membrane Reactor $\ldots \ldots \ldots \ldots \ldots$

3. Comparison of UV Light Intensity of Frosted Quartz Rods With Bare Optical Fiber . . 7

4. TCE Concentration of Permeate at Three Different Flow Rates in Laboratory Reactor . 8

5. Photocatalytic Membrane Reactor System Shown Closed, Locked, and Secured..... . 11

6. Photocatalytic Membrane Reactor System Shown Secured to Building With Lock and Chain on Right Rear of Box

7. View of Inside of Security Box with Pump in Foreground, Light Source in Rear and Bank of Four Membrane Retorts Mounted on Inside Wall on Left

8. View of Inside of Security Box Showing Prefilter in Background with Pump and UV

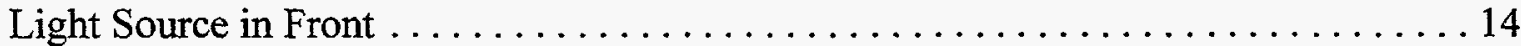

9. View of Four Membrane Retorts Mounted to Inside of Left Wall of Security Box . . . 15 


\section{ACRONYMS AND ABBREVIATIONS}

$\begin{array}{lll}\AA & - & \text { angstroms } \\ \text { CRADA } & - & \text { cooperative research and development agreement } \\ \text { GC } & - & \text { gas chromatograph } \\ \text { in. } & - & \text { inches } \\ \text { min. } & - & \text { minutes } \\ \text { ml. } & - & \text { milliliters } \\ \text { MS } & - & \text { mass spectrometer } \\ \text { mW } & - & \text { milliwatts } \\ \text { PORTS } & - & \text { Portsmouth Gaseous Diffusion Plant } \\ \text { ppb } & - & \text { parts per billion } \\ \text { ppm } & - & \text { parts per million } \\ \text { psig } & - & \text { pounds per square inch gauge } \\ \text { RCRA } & - & \text { Resource Conservation and Recovery Act } \\ \text { TCE } & - & \text { trichloroethylene } \\ \mu \mathrm{m} & - & \text { micrometer } \\ \text { UV } & - & \text { ultraviolet } \\ \text { VOCs } & - & \text { volatile organic compounds } \\ \text { W } & - & \text { watts }\end{array}$




\section{ACKNOWLEDGMENTS}

This report on the development and field testing at the DOE Portsmouth Gaseous Diffusion Plant of an innovative method to decompose volatile organic compounds in water is based on the combined efforts of individuals at Oak Ridge, Portsmouth Gaseous Diffusion Plant, and others. Project sponsorship has been provided through the DOE Office of Nuclear Energy and DOE Office of Environmental Restoration.

The following individual are specifically recognized for their valuable contributions to the project (in alphabetical order):

Dr. John Sheppard

Dr. William Van Dyke

Dale Adcock

Jim Ervin

Dave Mason

Curtis Miller

Brad Partain

Mark Pelfrey

Lawrence Powell

Tilak Raj

Roger Riddlebarger

George Roettger

Robert Stephenson

John Stockdale

T. David Taylor
- $\quad$ DOE Site Office, Portsmouth Gaseous Diffusion Plant

- $\quad$ DOE Office of Nuclear Energy

- $\quad$ LMES Membrane Technology Division

- $\quad$ LMES Construction Engineering

- $\quad$ LMES Acting Deputy Director of EMEF

- $\quad$ LMES Membrane Technology Division

- $\quad$ LMES Project Management

- $\quad$ LMUS Utilities Operations

- $\quad$ LMES Membrane Technology Division

- $\quad$ LMES Membrane Technology Division

- $\quad$ LMUS Utilities Operations

- $\quad$ LMES Membrane Technology Division

- $\quad$ LMES Membrane Technology Division

- $\quad$ Consultant to LMES

- $\quad$ LMES Site Manager, Portsmouth Gaseous Diffusion Plant 


\section{EXECUTIVE SUMMARY}

A small-scale demonstration of a new photocatalytic membrane reactor was undertaken at the X-623 Groundwater Treatment Facility at the Portsmouth Gaseous Diffusion Plant. The photocatalytic membrane reactor initially removed between 60 and $65 \%$ of the TCE in a single pass. It also removed significant amounts of three additional compounds (including completely removing one of the compounds). It is believed that these compounds were vinyl chloride, and two isomers of dichloroethylene. Within three days from startup, high suspended solids (mainly bacteria) contained in the feedwater tank caused plugging of the system's prefilter. The high concentration of bacteria was the result of a previously unknown large amount of activated carbon present in the feed tank prior to addition of the groundwater. It was also later discovered that fine colloidal silt particles had fouled the photocatalytic membranes and reduced their activity yielding only about a $20 \%$ reduction of TCE. The silt particles were determined to be between 50 and $100 \mathrm{~nm}$ and were able to pass through the $500 \mathrm{~nm}(0.5 \mu \mathrm{m})$ diameter pores of the prefilter. The results of this field test demonstrated the potential for success of the deployment of this technology, the simplicity, flexibility, and operability of the process and that improvements to the system design are needed prior to any future demonstrations. 


\section{Inorganic Photocatalytic Membranes \\ for the Remediation of VOCs in Groundwater at the Portsmouth Site}

\subsection{PURPOSE AND BACKGROUND}

Trichloroethylene (TCE) and other volatile organic contaminants are present in aquifers at a number of U.S. Department of Energy (DOE) sites. At the Portsmouth, Ohio, Gaseous Diffusion Plant (PORTS), TCE is present in groundwater at several independent plumes from the low parts per billion ( $\mathrm{ppb}$ ) range to approaching saturation at approximately 1,000 parts per million (ppm). In order to assure containment of the contaminated groundwater to the PORTS site, five groundwater pump and treatment facilities are in operation treating approximately 23 million gallons per year at a cost of over $\$ 3$ million per year. This work was motivated by the need to find a more efficient, cost effective treatment method for these aquifers.

The purpose of this work was to develop a photocatalytic membrane reactor to decompose volatile organic compounds (VOCs) in groundwater and demonstrate this technology at an operating groundwater treatment facility at the Portsmouth Gaseous Diffusion Plant. Currently, groundwater containing VOCs is pumped from two pumping wells and from a holding pond into an air sparger which removes a large fraction of the VOCs. This water is then pumped through an activated carbon bed to adsorb the remaining VOCs. This is commonly referred to as a pump and treatment facility. This carbon must be replaced or regenerated periodically and the used absorbent must be handled as RCRA waste. The carbon bed in a pump and treatment facility can be replaced with a photocatalytic reactor (see Figure 1). The photocatalytic membrane reactor has the potential to produce significantly less waste and has a very long lifetime.

Photocatalysis is a process in which a semiconductor (normally $\mathrm{TiO}_{2}$ ) is activated by the absorption of light to decompose organic compounds. When $\mathrm{TiO}_{2}$ is illuminated by ultraviolet (UV) light with a wavelength less than $380 \mathrm{~nm}$, valence electrons can absorb photons exciting them from the valence band to the conduction band where they are free to move around the crystal. The holes left behind in the valence band can diffuse to the crystal surface and produce surface hydroxyl radicals which participate in oxidation reactions. The free electrons can diffuse to the crystal surface and participate in reduction reactions.

Currently photocatalysis is generally accomplished by one of two methods. The most commonly employed method utilizes a suspension of small anatase $\mathrm{TiO}_{2}$ particles in water containing ppm concentrations of organic contaminants. The $\mathrm{TiO}_{2}$ particles in the suspension are illuminated by ultraviolet light. As the contaminants diffuse through the water and come in contact with the $\mathrm{TiO}_{2}$ particles, they are decomposed into innocuous components such as carbon dioxide and water. A separation is then required to recover the $\mathrm{TiO}_{2}$ catalyst and produce clean water. This recovery makes the method difficult to use on a continuous basis. Another method utilizes sol-gel techniques to coat the inside of a glass reactor tube. The tube is illuminated from the outside by conventional "black light" bulbs. The contaminant compounds must diffuse through the water to the surface of 


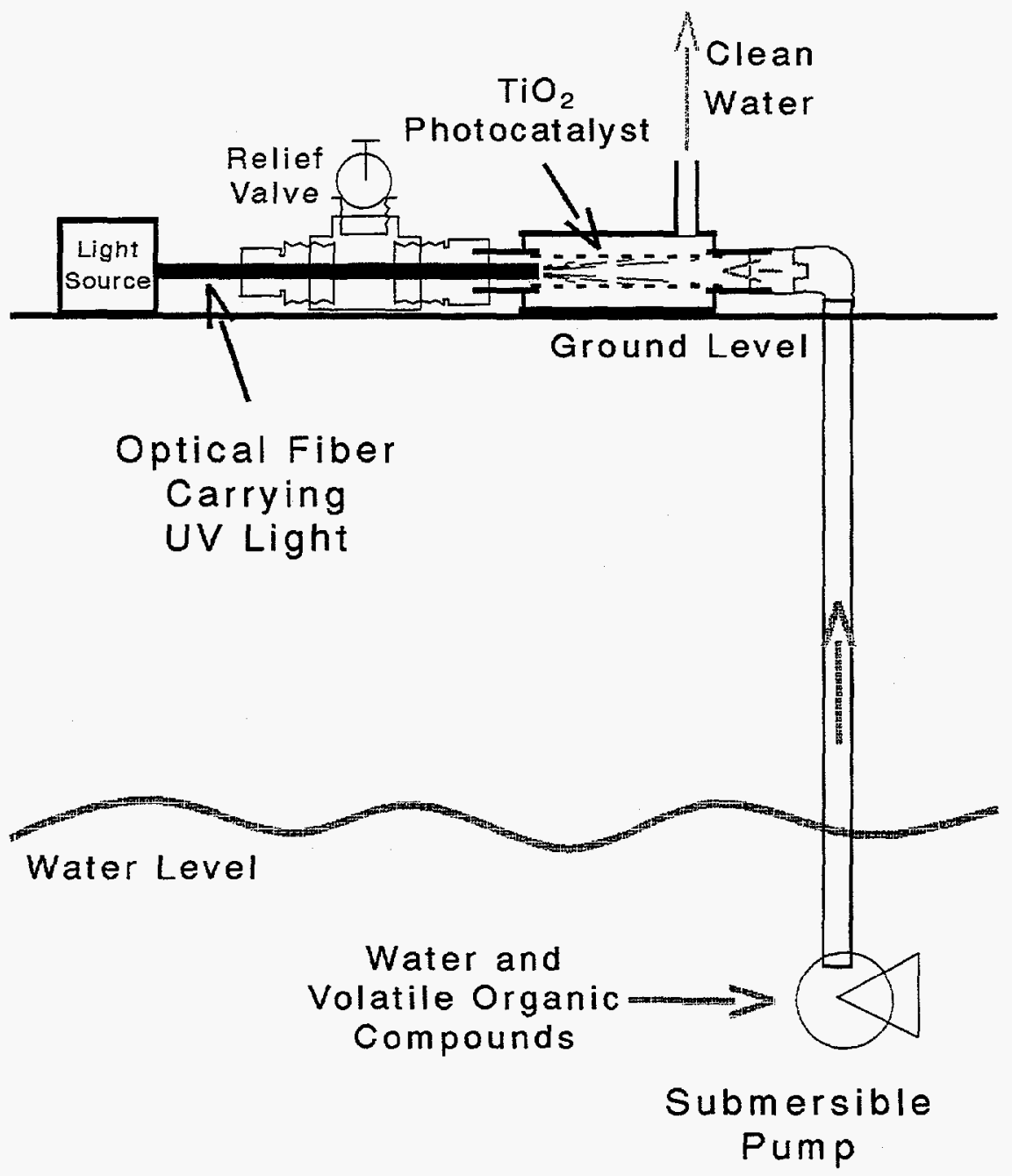

Figure 1 Schematic of Pump and Treat Photocatalytic Reactor for the Destruction of VOCs in Groundwater. 
the illuminated catalyst on the glass tube before they are decomposed. This method requires no separation of catalyst from the process stream. However, it does require the contaminated liquid to pass through the reactor many times to ensure that all of the contaminant molecules have come into contact with the catalyst surface.

The Membrane Technology Division at the East Tennessee Technology Park has designed a new photocatalytic reactor. It is based on a photocatalytic membrane. This design, which is being patented by the Department of Energy, combines advanced membrane technology and fiber optic light delivery. This new technique overcomes the obstacles encountered above and also allows for ease of scale-up. This invention couples a mercury arc lamp with an optical fiber to carry the light to the photocatalytic reactor. The polished end of the fiber acts as a mini flashlight to illuminate the interior of the photocatalytic membrane. More advanced methods for illuminating the membrane surface are being investigated. The water containing the contaminant molecules is

forced through the porous membrane by pressure. The pores of the membrane are very small and form an extremely large number of very narrow passage ways through the membrane. The distance between a contaminant molecule and the $\mathrm{TiO}_{2}$ is significantly reduced which greatly increases the probability of a contaminant molecule contacting the catalyst. The probability of contact can be further increased by decreasing the pressure to decrease the flow rate of water through the membrane. The control of the flow rate can achieve any desired degree of contaminant removal, even complete removal in a single pass through the reactor.

One of this reactor's best features is its ability to be scaled up. It was this attribute that prompted the demonstration of this technology at an existing PORTS groundwater treatment facility. A module can be fabricated having an arrangement of many tubular membranes with each tube being illuminated by a single fiber from a fiber bundle coupled to a high energy UV light source. The use of fiber optics for light delivery allows the light source to be located remotely from the photocatalytic membrane. This offers an important advantage for location and maintenance. It may even provide the possibility for in-situ groundwater treatment.

This work was accomplished in two phases. The first, the development phase required many laboratory measurements on several variations of the membrane structure. After the development work on the individual membranes was completed, a prototype membrane was selected. An appropriate number of these membranes were fabricated and then assembled into a small photocatalytic reactor. This reactor was to be tested for two weeks in the X-623 Groundwater Treatment Facility at the Portsmouth Gaseous Diffusion Plant. This facility was chose because it is inside of the Limited Security Area at PORTS which would allow the evaluation of classified technology. This demonstration utilized a slipstream approach where only a small fraction of the process stream was diverted to our test system. 


\subsection{LABORATORY WORK}

Even though previous results showed significant decomposition of trichloroethylene (TCE), improvements were needed to demonstrate the efficiency and economics of the process for large scale commercial application. The development effort needed to improve the characteristics of the photocatalytic membranes and to evaluate the operating range for the membrane. There were three major features of the system that were evaluated. First, determine what materials and fabrication scheme would produce the membranes having the highest photocatalytic activity. Second, determine the desired operating conditions (flow rate, trans membrane pressure, percent cut, etc.) that would yield the best TCE removal efficiencies. And lastly, how could the amount of light and uniformity of the light distribution be improved.

The laboratory test system (See Figure 2) consisted of a glass supply vessel, a variable speed gear pump, a back-pressure regulator, and a membrane housing (also referred to as a retort). All tubing and fittings used in the system were made from either Teflon or stainless steel to minimize contamination. The water containing TCE would be placed into the supply vessel. The solution was pumped through the inside of the photocatalytic membrane. The reject stream was fed to a backpressure regulator which was used to control the amount of pressure across the membrane. From the regulator, the reject was fed back into the supply vessel. By varying the speed of the pump and the tran membrane pressure, the percent cut could be varied from 0 to $100 \%$. The permeate stream, which was collected in the shell of the retort could be collected in a vial for analysis using a gas chromatograph with mass selective detector (GC/MS). The UV light was supplied by a 100W mercury arc lamp (Oriel Corp.). UV light having a wavelength of less than approximately $385 \mathrm{~nm}$ is capable of creating active sites on the photocatalytic surface. The light was coupled to both optical fibers and liquid light guides by using the appropriate lens system. The end of the fiber or light guide was then coupled to a quartz rod which was sealed into the system using a pass-thru compression fitting and Teflon ferrules. The light was transported down the length of quartz rod and out the end of the rod to illuminate the inside of the photocatalytic membrane.

Several different methods for making membranes were investigated. First generation tubes were tested in the reactor at trans membrane pressures of 15-30 psi which corresponded to permeate flow rates of $20-40 \mathrm{ml} / \mathrm{min}$. Pump flow rates were kept constant at about $300 \mathrm{ml} / \mathrm{min}$. At these flow rates less than $10 \%$ of the TCE was removed from the permeate. Transmembrane pressures were decreased to five psi with only a slight improvement in TCE destruction rates.

The reactor was then modified slightly and a new retort was fabricated. This retort offered the added ability to drain the retort, let it refill, then collect that solution. This new design assured that the solution that was collected was fresh permeate. The previous design only had an outlet at the top of the retort. When the permeate completely filled the inner shell of the retort, the overflow would then flow out through a tube at the top. This is the liquid that was collected for analysis. The solution coming out of that tube was not necessarily a representative sample of the permeate over the last several minutes. When the flow rate was slowed down, the sample collected would include solution that had permeated through the membrane much earlier. 


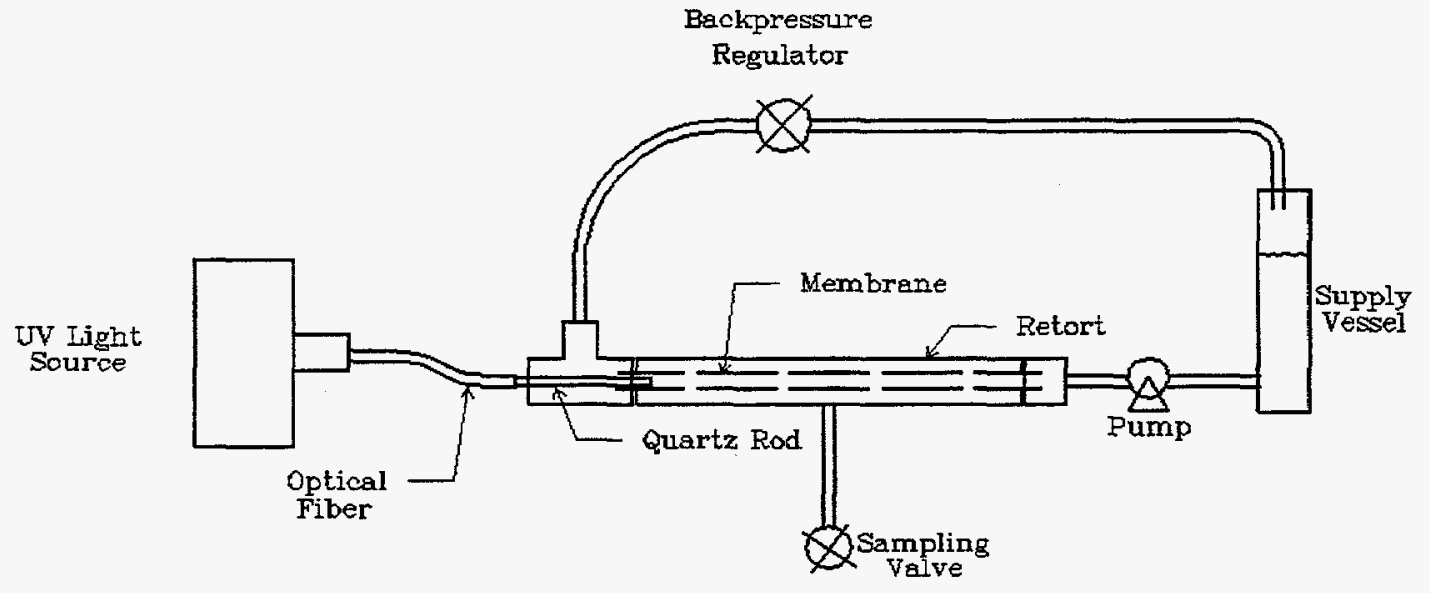

Figure 2 Schematic drawing of laboratory photocatalytic membrane reactor. 
In order to reduce the flowrate to increase the TCE removal efficiency, a new pump was installed. This metering pump had a maximum flow rate of eight $\mathrm{ml} / \mathrm{min}$. This allowed operation of the system with $100 \%$ cut and with a controlled permeate flow rate.

When the flow rate was decreased to $0.5 \mathrm{ml} / \mathrm{min}$ the TCE concentration was reduced by over $60 \%$. This improvement in decomposition rate led to an improvement in the fabrication of the next generation membrane. This improvement in fabrication method reduced leak rates through defects significantly. This membrane, when tested with a flow of about $1 \mathrm{ml} / \mathrm{min}$, reduced TCE by approximately $82 \%$.

The next major improvement came in the light delivery system. Although, the light coming out of the end of the quartz rod did a reasonably good job of illuminating the inside of the photocatalytic membranes, there was still a factor of at least three to five variation in light intensity along a six inch length. In order to optimize the process, it was necessary to modify the quartz rod so that it glowed uniformly along its length. Because the light internally reflects inside the quartz rod when it encounters smooth surfaces, the surface of the quartz needed to be roughened. First, a quartz rod was frosted by passing a sandblasting nozzle containing alpha alumina along its length. When coupled to the UV light source, it did glow along the frosted area. However, most of the light had escaped in the first three to four inches. Then several methods for putting a graduated frosting were tried. When the quartz rod was placed in a lathe and sandpaper was held against it a varying pressures, a graduating frosting resulted. This yielded less than $20 \%$ variation in intensity over a seven inch section of tube (Figure 3).

This new light delivery method improved the TCE removal rate to $94 \%$ at one $\mathrm{ml} / \mathrm{min}$. The effect of permeation rate was then studied. The flow rate was increased to two $\mathrm{ml} / \mathrm{min}$ which resulted in about an $89 \%$ removal and increasing the flow to $4 \mathrm{ml} / \mathrm{min}$ still resulted in a removal of $68 \%$ of the TCE (Figure 4). These results were compared to what you would expect based on a plug flow reactor (PFR) model. In a PFR, one makes the assumption that your reactor is a cylinder with a thin slice of material flowing through it. The model assumes there is complete mixing within that plug but that there is no mixing with plugs in front of or behind it. Each pore in our membranes can be visualized as a PFR because each pore is somewhat cylindrical. When using first order kinetics for the decomposition reaction the theoretical results compare favorably with the experimental results.

The next step was to take what was learned in the laboratory and build a scaled-up test system for testing of this technology on groundwater at PORTS. A new series of membranes based on the design which yielded the best photocatalytic removal efficiencies were fabricated for the demonstration. A sample membrane from this series was evaluated in a modified laboratory test system with good results. 


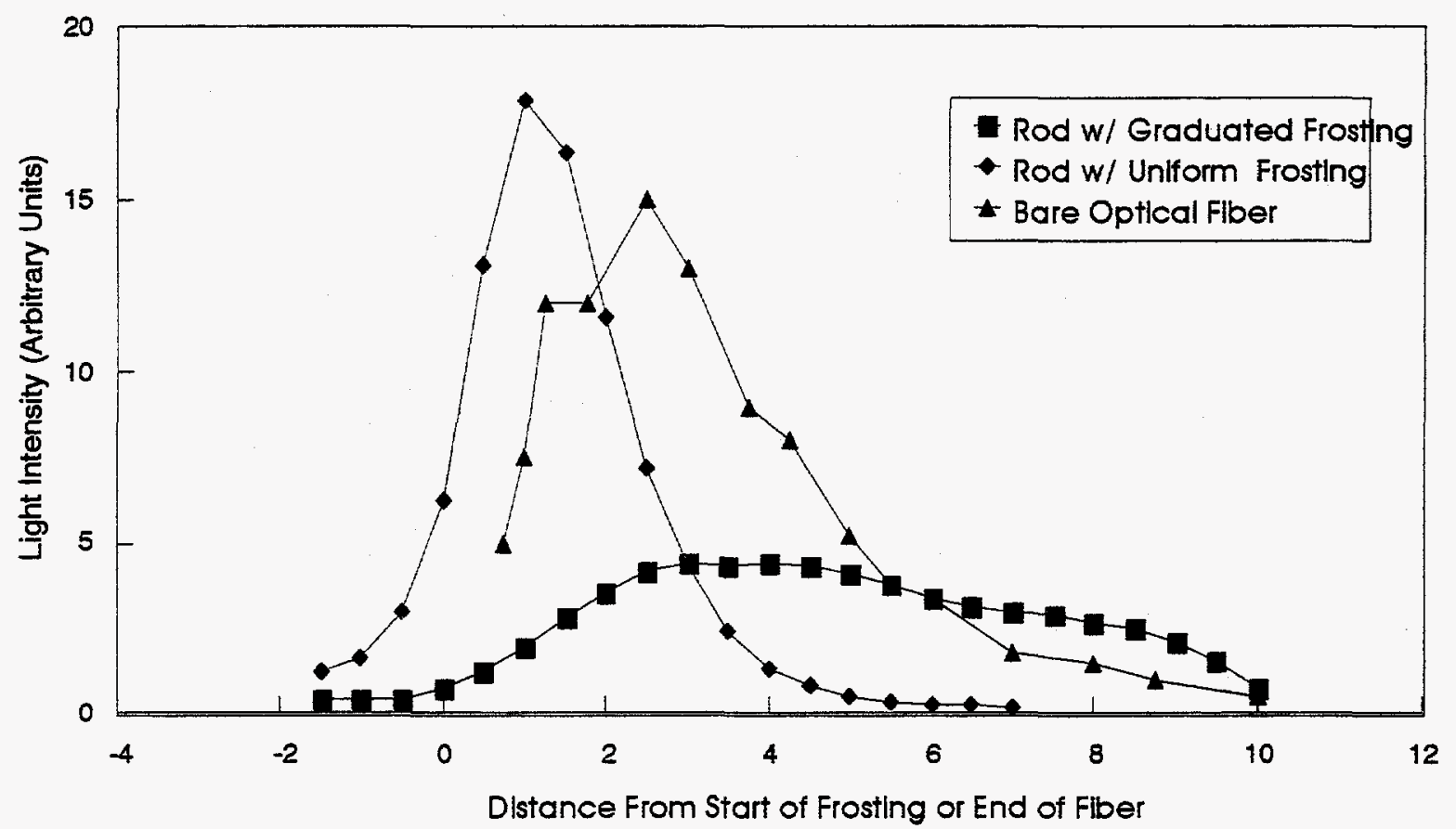

Figure 3 Comparison of UV light intensity of frosted quartz rods with bare optical fiber. 


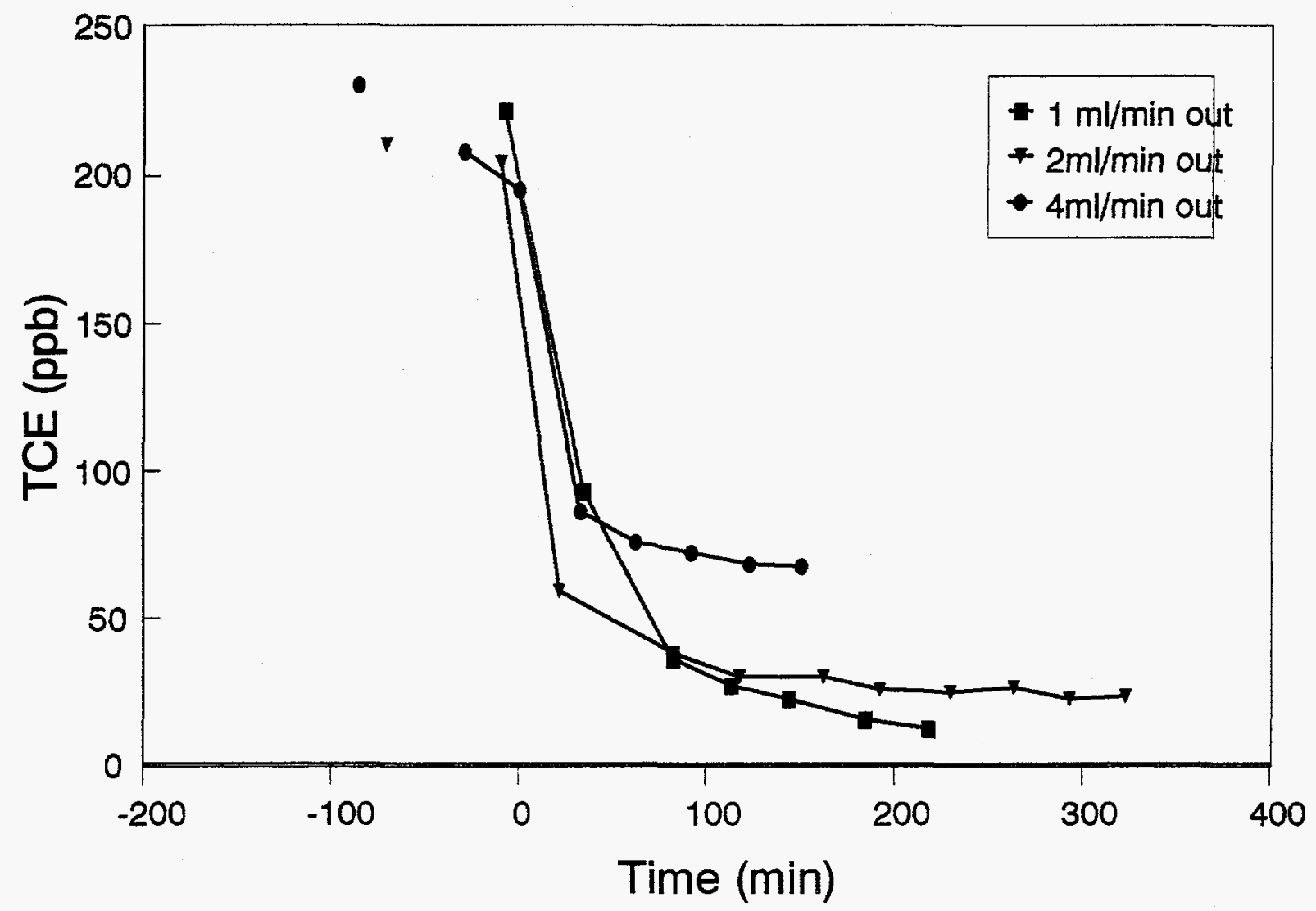

Figure 4 TCE concentration of permeate at three different flow rates in laboratory reactor. 


\subsection{PORTSMOUTH FIELD TEST}

It was decided that an appropriate field test would entail the processing of $100 \mathrm{ml}$ per minute of TCE contaminated groundwater while removing $75 \%$ of the TCE in a single pass. Based on the results obtained in the laboratory, a system containing 12 tubes having a diameter of $3 / 4$ of an inch and a length of about nine inches could process the amount of water desired. In order to illuminate 12 photocatalytic tubes using a single light source, a means to split the line was required.

The light source is a $100 \mathrm{~W}$ mercury arc lamp from Oriel Corporation. It has a housing which can be coupled to four sets of optics or two sets of optics with reflectors in the other two positions to increase the light intensity at the two sets of optics. The most practical means of illuminating 12 tubes simultaneously would be to couple the light source to two fiber bundles with each bundle separating to six individual fibers. After consulting with several vendors, two special order hexfurcated fiber bundles were purchased from Oriel. These bundles would consist of six $200 \mu \mathrm{m}$ UV fibers bundled together at one end with the six fibers terminated individually at the other end. Because these bundles were a special order item a 10-12 week delivery date was given.

Upon receipt of the fiber bundles, they were coupled to the light source and tested. The resultant output from the six single fibers was much less than expected. The output from each fiber was measured to be between four and five $\mathrm{mW}$ of UV light. The output from a single three mm liquid light guide was determined to be between 270 and $280 \mathrm{~mW}$. Based on packing densities of the fibers in the bundle it was expected that between $50 \%$ and $67 \%$ of the light that was focused on the bundle's cross-section would be collected by the six fibers. Therefore, between 20 and $30 \mathrm{~mW}$ of UV light was expected from each of the six fibers.

The six fibers were arranged with one fiber in the middle with the remaining five arranged in a ring around the center. The $200 \mu \mathrm{m}$ fibers each had a cladding thickness of $25 \mu \mathrm{m}$. This yielded an approximate diameter of the bundled fibers of $700 \mu \mathrm{m}(0.7 \mathrm{~mm})$. In theory, this size bundle should have coupled adequately with arc lamp being used. The lamp has an arc size of $0.6 \mathrm{~mm} \times 0.6 \mathrm{~mm}$ when new. The condenser lens for this system and associated optics are designed to image an arc with no increase in magnification. Therefore, it was believed that this system should be able to focus this lamp into our fiber bundle. However, as this lamp is aged the electrodes are eroded away and the arc size increases.

In addition, these optics cannot focus all wavelengths of light to the same point. Because we are trying to utilize all available UV light, we need to be able to focus all light having a wavelength of less than $380 \mathrm{~nm}$ into the fiber bundle. Also, upon further investigation it was determined that the lenses magnify the image slightly. Adding all of these factors, it was understandable why our fiber bundles were not acting as expected. In order to collect all of the available light, it is believed a bundle having larger fibers was needed.

In order to prevent further delaying the start of the demonstration by waiting for delivery of new fiber bundles, it was decided to complete the demonstration with only four photocatalytic membrane 
tubes. This reduction in membrane area corresponded to a reduction of the desired flow rate from $100 \mathrm{ml} /$ minute to less that $40 \mathrm{ml} /$ minute. Each of these membranes could be illuminated using a larger single fiber or light guide coupled to one of the four ports on the lamp housing. Therefore, two more sets of optics along with additional liquid light guides were ordered. Since these were not special-order items, the equipment was received in approximately two weeks.

The complete test system was assembled in Oak Ridge (See Figures 6-9). The system consisted of a pump, flowmeter, prefilter, photocatalytic membranes, back-pressure regulator, and light source. The complete system was mounted in a Knaak Jobbers Box (Figure 5) having inside dimensions of $22 " x 23 " x 70$ ". This box was required to meet the specifications in the PORTS Security Plan for the protection of the classified materials in this system. The groundwater flowed through flexible teflon tubing through a hole in the box to a peristaltic pump. This pump had a variable flow rate up to 4000 $\mathrm{ml} /$ minute and a maximum pressure rating of $30 \mathrm{psi}$ which was more than adequate for our needs. The water then flowed through a digital flow meter for monitoring the flow rate.

The groundwater was then run through a prefilter in order to minimize the possibility of suspended particles in the groundwater from fouling the photocatalytic membranes and reducing the amount of light reaching the surface. This prefilter, fabricated in the laboratory of the Membrane Technology Division, consisted of 37 tubes sealed into a stainless steel shell and had a pore diameter of approximately $0.5 \mu \mathrm{m}$. Because the prefilter was designed to handle much higher flows than were expected to be realized during this demonstration and the groundwater flowed through several bag filters before entering our system, the filter elements were sealed at one end resulting in a $100 \%$ cut.

The water then flowed into a set of four photocatalytic tubes. These four tubes were selected from a series of 12 tubular photocatalytic membranes that were fabricated for the demonstration. The four tubes were arranged in parallel so that variations in performance of each tube could be evaluated independently or the outputs combined to a common output. The inlet to the tubes consisted of a manifold having one inlet and four outlets. The manifold outlets were all fitted with ball valves for shutting off the water to that tube in the case of a failure of that membrane. Each of the four membranes was enclosed in a retort. The retort was a shell that sealed around the membrane to collect the permeating groundwater. The outlet from each retort was fitted with a three-way ball valve. This valve allowed the directing of the permeating water to one of two places. Either the permeate was sent to a manifold which combined the permeate streams of the four tubes together or it was sent it to a sample port that could be used to collect samples from individual membranes in order to evaluate the relative performance of the four photocatalytic membranes. 


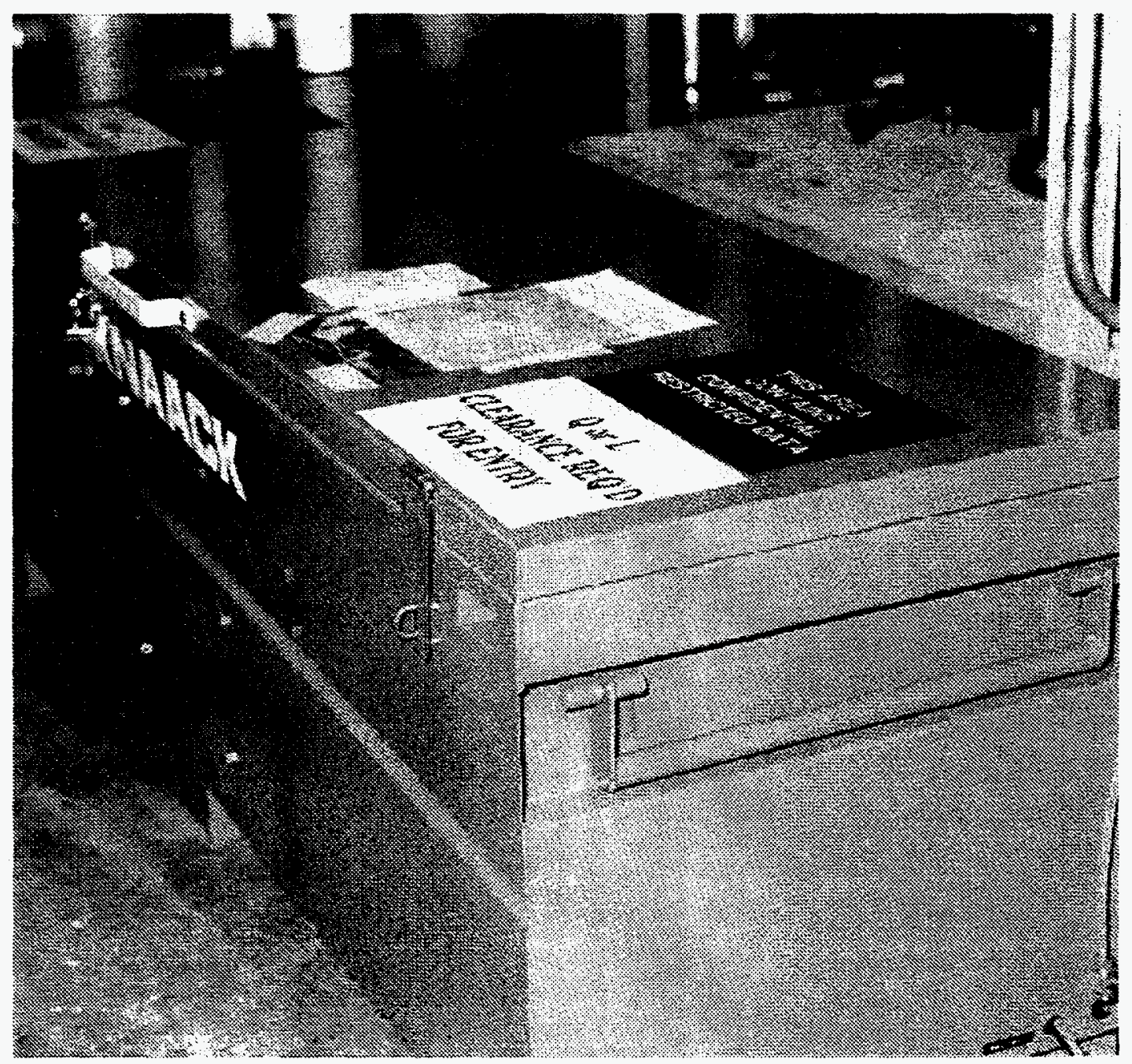

Figure 5 Photocatalytic Membrane Reactor System Shown Closed, Locked, and Secured. 




Figure 6 Photocatalytic Membrane Reactor System Shown Secured To Building With Lock And Chain On Right Rear Of Box. 


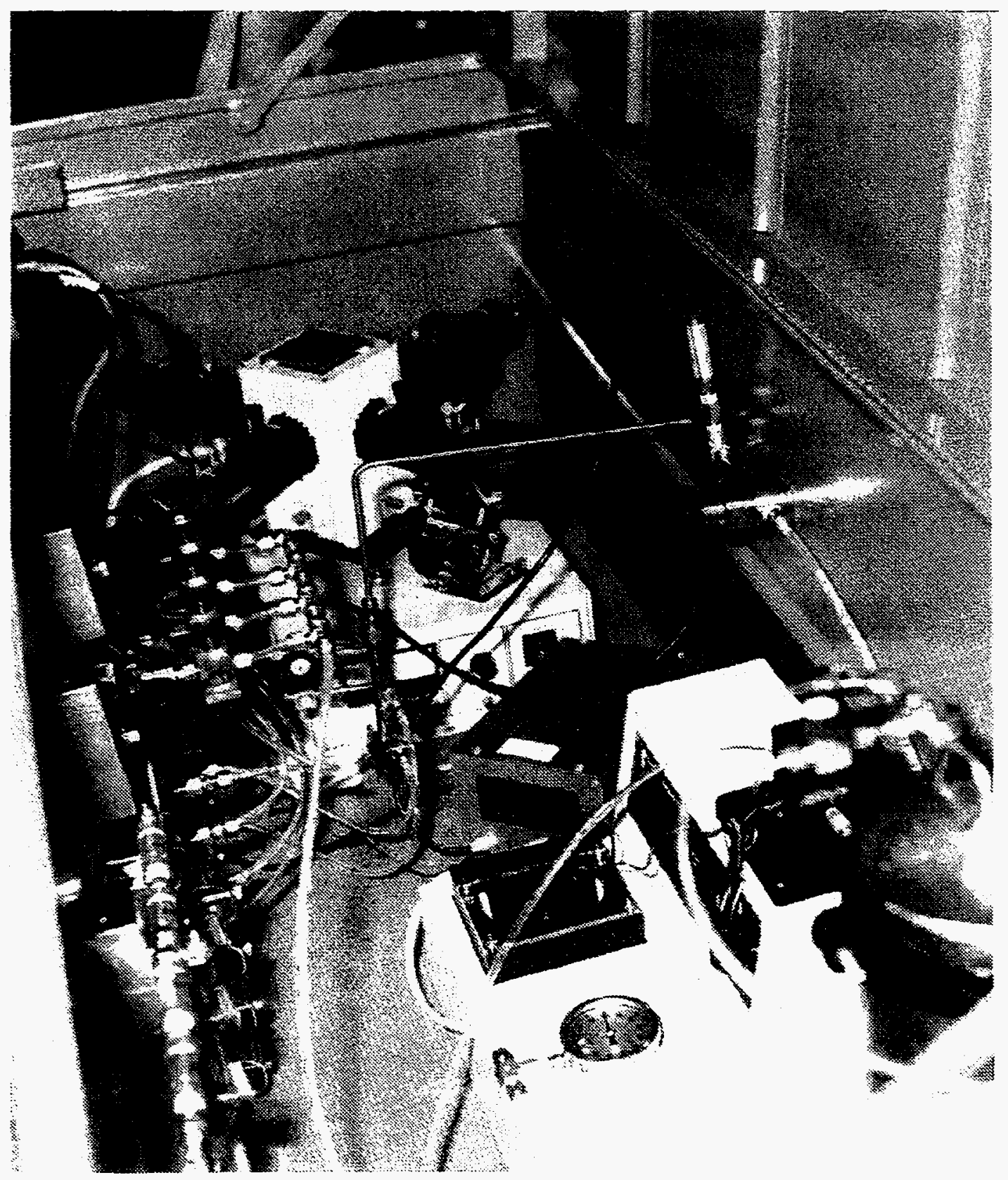

Figure 7 View of Inside Of Security Box With Pump In Foreground, Light Source In Rear And Bank Of Four Membrane Retorts Mounted On Inside Wall On Left. 


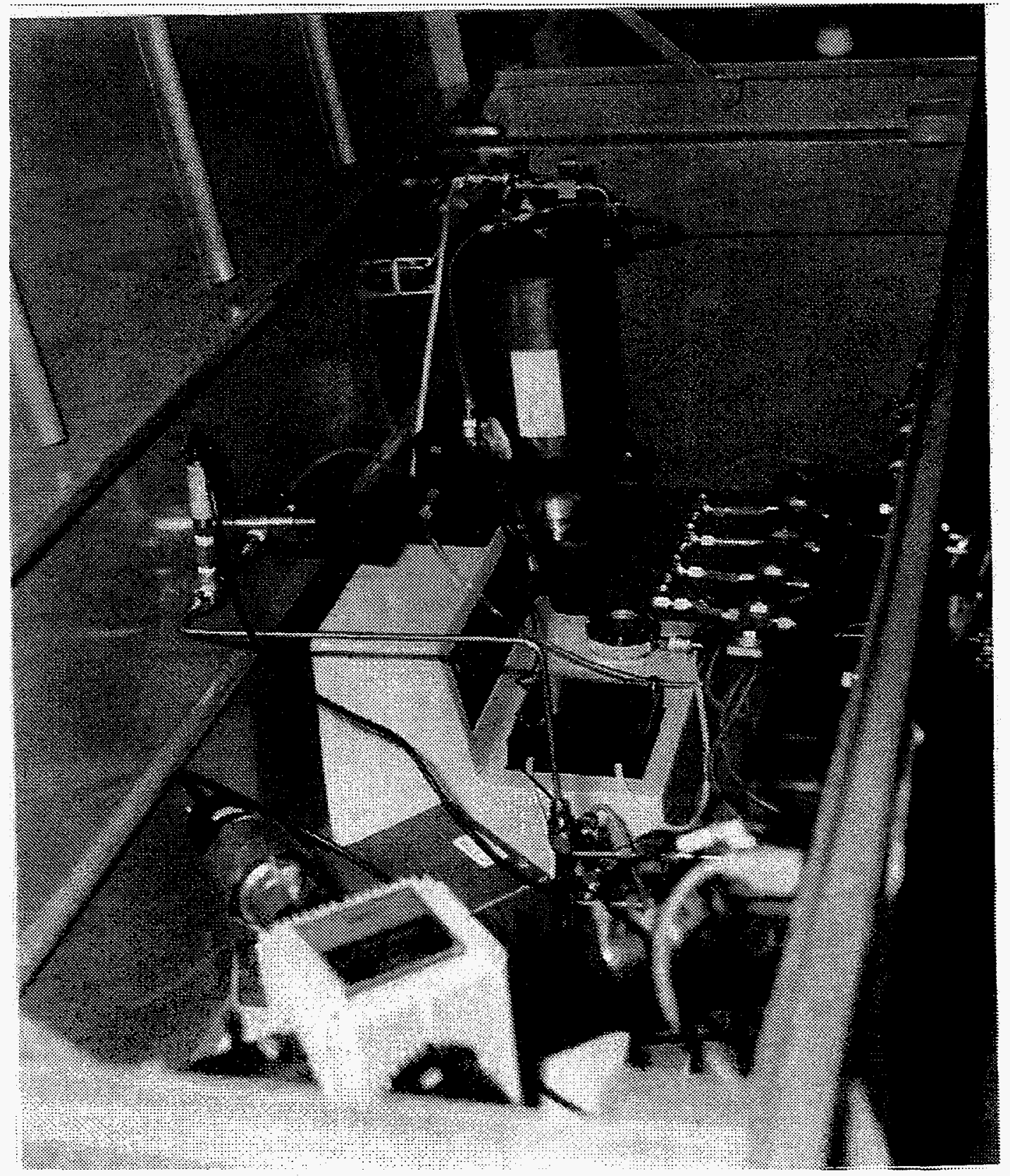

Figure 8 View Of Inside Of Security Box Showing Prefilter In Background With Pump And UV Light Source In Front. 


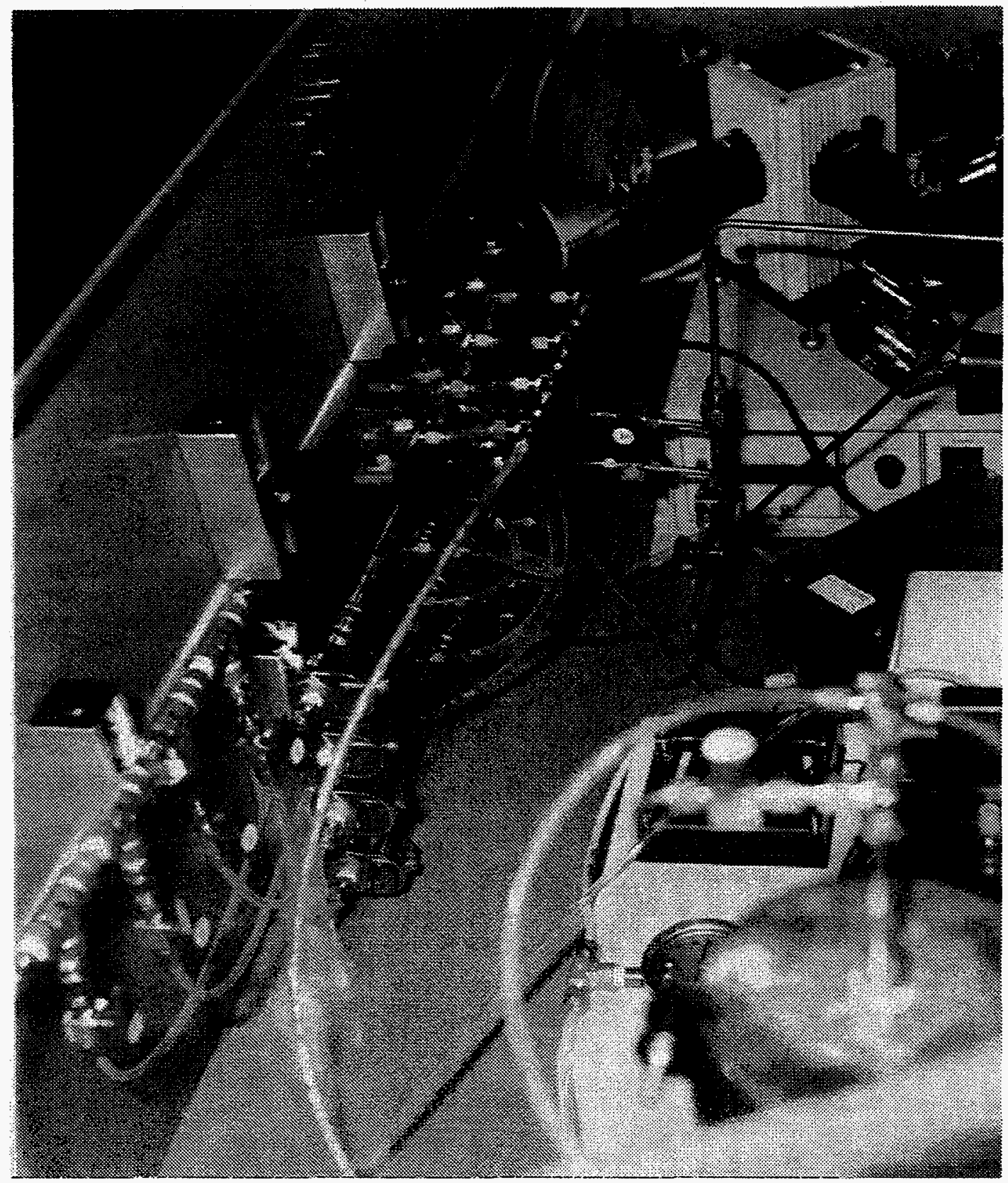

Figure 9 View Of Four Membrane Retorts Mounted To Inside Of Left Wall Of Security Box. 
The reject streams (the water that flowed straight through the membrane tubes) was also combined using a manifold. The outlet of this manifold was sent to a pressure transducer and back-pressure regulator. This back pressure regulator served as an adjustable pressure relief valve. The photocatalytic membranes were run at $100 \%$ cut. Therefore if for some reason the membranes were to completely plug, the water would relieve out this regulator and into the drain preventing damage to the membranes or any other component in this system. Although this system was being operated at $100 \%$ cut, this regulator could have also been adjusted to keep this system running at constant pressure and allowing the excess water to be recycled back to the $\mathrm{X}-623$ treatment system.

At the time when the field demonstration was scheduled to begin, the groundwater at the X-623 site had high levels of acetone due to an earlier groundwater treatment demonstration. Isopropanol was one of a series of tracers that had been injected into a small test section of the X-701B plume several months earlier to aid in the identification of quantities and locations of DNAPL. Acetone apparently is a breakdown product of the isopropanol. Acetone, present at concentrations of over $10 \mathrm{ppm}$, was expected to compete with the photocatalytic reaction of TCE. Laboratory results using methanol at those levels indicated that a reduced TCE destruction rate could be expected when other organic compounds were present. It was hoped that the level of acetone would decrease significantly if the project were delayed for several weeks.

After several weeks of delay, the acetone levels had not decreased significantly. To avoid any further delays, groundwater from a different site that did not have the acetone problems was used. Because all of the other desired groundwater sites were outside of the Limited Security Area, the decision was made to conduct the demonstration in X-623 but with groundwater from X-625. Groundwater was brought to X-623 on February 18, 1997, in a tanker truck and pumped into a stainless steel storage tank in the facility.

On February 19, personnel from Oak Ridge traveled to Portsmouth with the photocatalytic membrane reactor system. On the following day the system was installed in X-623, the system was secured to the building, the water lines were connected from the storage tank, and the UV light source was turned on. Initial pressure at the inlet to the prefilter was around $10 \mathrm{psi}$ and at the photocatalytic membranes about 15 psi.

The following day, samples were collected for analysis. Samples were analyzed by gas chromatography (GC) using purge and trap sample injection and a flame ionization detector. This $\mathrm{GC}$, located in X-625, is calibrated to quantify the concentration of TCE only. Results of samples analyzed at X-625 indicated a $60 \%$ reduction of TCE from an inlet of approximately $180 \mathrm{ppb}$. The chromatogram for the inlet water contained three additional peaks indicating the presence of at least three additional volatile organic compounds. However, in the chromatogram of the system effluent, one of the peaks was missing indicating a complete removal of that material. The three remaining peaks (TCE plus two additional) were significantly smaller in size. Qualitative analysis of these two additional peaks revealed approximately $60-80 \%$ removal of these two compounds. It is believed that these additional peaks corresponded to vinyl chloride, which was completely removed and two 
isomers of dichloroethylene. Because of the competition between the TCE and the three additional compounds present in the groundwater, higher TCE removal efficiencies (than were realized during this field test) would be expected if TCE were the only compound present.

On February 24, 1997, Portsmouth personnel reported that the pressure across the prefilter has risen substantially (to over $40 \mathrm{psi}$ ) and the flow rate had decreased indicating that the prefilter had become plugged. Bacteria was suspected because the feedwater was being drawn from a stagnant tank. The appearance of the feedwater also changed dramatically over the previous six days. When the demonstration was started the water looked very clean, but now was almost opaque with a orangeyellow color and the feedwater also had a very bad odor.

A backflush of the prefilter was attempted with sanitary water with no luck. Bleach was then added to the backflush water but still no improvement (decrease) was observed in the pressure drop. Hot water (approx. $70{ }^{\circ} \mathrm{C}$ ) containing bleach was then employed. After a few minutes it was observed that the clear Teflon tubing connected to the waste side of the prefilter was black. A few minutes later a thick black liquid started coming out of the backflush line. Backflushing continued for about six hours. Because there was still a black solution coming out or the prefilter, the prefilter module was disassembled. Upon opening the module (about 18 inches long and 6 inches in diameter), clumps of black material came out. The inside of the tubular filters were completely black while the outside of the tubes had a very small amount of black material. Therefore it appears that our prefilter was effective in removing the suspended material. However, it appeared a very small amount of suspended material passed through the filter.

The stainless steel tank was cleaned and refilled with new groundwater. Upon opening the drain valve on the tank, clumps of black particulates came out with the water. This tank was used to collect the backflush from the carbon filters that are used to remove the TCE under normal operation. Apparently, some of the carbon and other suspended solids from the carbon vessels remained in the tank and caused the plugging in the prefilter. It was then decided to bring in a small tank ( 400 gal.) to be used as the feed vessel so it could be monitored more easily for suspended material. A plastic tank was brought in and filled with water from X-622. Tubing was used to connect this new tank to the treatment system. The system was restarted and appeared to be working fine again.

On March 4, 1997, the online gas chromatograph stopped working properly. The routine operational performance samples were then collected and stored for analysis in Oak Ridge. On March 10, 1997, Oak Ridge personnel traveled to Portsmouth to replace the mercury arc lamp. It had burned out sometime that morning between $8 \mathrm{AM}$ and noon. It is a research grade light source and is not designed for long term use. On March 11, 1997, samples were transported to Oak Ridge for analysis.

Analysis of the samples indicated removal of only $20-25 \%$ of the TCE. It was assumed that the photocatalytic membranes must have been fouled by the suspended material and needed to be replaced. On March 14, 1997, new photocatalysis membranes were transported to Portsmouth and installed. It was observed that the membranes had an opaque layer of material on the inside. The system was restarted using the new membranes. The following week, samples of the first set of 
membranes were submitted for investigation by scanning electron microscopy (SEM) to identify the dark material that was present on the membranes. The tubes had a dark film on the inside of the tubes. SEM analysis indicated that the surface of the membranes were coated with particles that were between 50 and $100 \mathrm{~nm}$ in diameter and were composed of mainly silicon and aluminum. Based on these results it was believed that the dark material was silt. This fine colloidal silt apparently passed through the $0.5 \mu \mathrm{m}$ prefilter but was retained by the approximately $600 \AA 0.06$ $\mu \mathrm{m})$ photocatalytic membrane.

On March 15, 1997, the treatment facility (X-623) had a power outage. The photocatalytic membrane system was restarted without incident. On March 25, 1997, personnel from Oak Ridge traveled to PORTS for a routine UV lamp replacement. While in PORTS, the photocatalytic tubes were removed and examined. Cleaning of the tubes was attempted and the tubes were reinstalled into the reactor. Additional groundwater samples collected over the previous 10 days were transported to Oak Ridge for analysis by GC/MS.

Analysis of the samples by GC/MS indicated approximately a $15 \%$ removal of TCE from the period of March 15 through March 24, 1997. There didn't appear to be any noticeable improvement in system performance from the new photocatalytic membranes. This is believed due to the unfortunate loss of power to the treatment facility on the day following the replacement of the photocatalytic tubes on March 14, 1997. Because of this power outage the UV lamp went out. By the time the system was turned back on and steady state was achieved, the new tubes must have already become somewhat fouled.

On April 2, 1997, the system was switched to using supply water from X-623. The feedwater was groundwater that had gone through an air stripping stage to reduce the TCE levels to less than 500 $\mathrm{ppb}$. However, in addition, the water also contained measurable quantities of acetone, dichloroethylene, and methylisobutyl ketone (MIK). Although the TCE concentrations continued to be reduced by approximately $20 \%$, qualitative results for the other compounds were inconclusive. This condition may have existed because of the large volume of groundwater contained in the system between where the inlet streams and effluent streams were sampled. The inlet collected was done prior to the prefilter. The prefilter and the tubing leading to the photocatalytic tubes contained over four liters of water. Because the flow rate was under $30 \mathrm{ml} /$ minute near the completion of the demonstration, the water collected in the effluent was treated water that entered the system several hours earlier. Unfortunately, a more logical point for the collection of inlet samples was not possible due to the requirements imposed on the system by PORTS security personnel due to the classified material present in the system.

On April 15, 1997, the system was shut down and demobilization began. On April 17, 1997, the system was transported to Oak Ridge. When the photocatalytic tubes were removed they were examined and appeared to be coated again with a dark material believed to be fine colloidal silt. The prefilter was opened and the inside of the tubes looked unchanged from the reassembly performed on February 27, 1997. 


\subsection{CONCLUSIONS}

The photocatalytic membrane reactor initially removed between 60 and $65 \%$ of the TCE in a single pass. It also removed significant amounts of three additional compounds (including completely removing one of the compounds). It is believed that these compounds were vinyl chloride and two isomers of dichloroethylene. A high concentration of bacteria, which caused plugging of the prefilter, and silt, which fouled the photocatalytic membranes, disrupted the long term evaluation of this system under field conditions. With all of the unforeseen problems that were encountered, the system proved to be operationally simple, resilient, and effective in destroying organic contaminants.

\subsection{FUTURE WORK}

There is currently a CRADA in place, partnering with Coors Ceramics, to further develop and demonstrate a photocatalytic membrane reactor. From this work it was learned that improved methods to deliver light to multitube modules needs to be researched. Also, methods to reduce membrane fouling need to be improved. An improve reactor would have either a prefilter with smaller pores that would reject the colloidal silt particles or would be run in a crossflow configuration or both. Also a method to easily backflush these membranes would be implemented if needed. The knowledge obtained during this demonstration with real contaminated groundwater will greatly improve the chances for success of a future demonstration. 
DISTRIBUTION

DOE

Robert Brown

Richard Meehan

Joe Parks

John Sheppard

Dr. William Van Dyke

LMER

John Clinard

\section{LMES}

Dale Adcock

Frank Anderson

Calvin Angel

William Biloski

Brian Bischoff

Paul Cross

Douglas Fain

Thomas Houk

Donald James II

Dave Mason

Gerry McGuire

Curtis Miller

Lawrence Powell

Tilak Raj

George Roettger

Chuck Scheibly

Robert Stephenson

John Stockdale

Dave Taylor

File-RMDC Center-RC

File-Program Planning \& Integration

LMUS

Mark Pelfrey

Roger Riddlebarger

Technical Information Office (2)

Pall Corporation

John Farris

Steven Geibel

Lawrence Weber

Donald Stevens

\section{Coors Ceramics Company}

Woody Howe

John Ghinazzi 